\title{
Argumentação científica e educação pela pesquisa: o parecer de professores(as) a uma prática pedagógica
}

Scientific argumentation and teaching thru research: the opinion of teachers on a pedagogical practice

\author{
Agnaldo Ronie Pezarini ${ }^{1}$ \\ Samuel Mendonça²
}

\section{Resumo}

O presente artigo apresenta como escopo central a interface entre a Argumentação Científica (AC) e a Educação Pela Pesquisa (EPP). É sabido que educar é uma prática ampla e promover esse educar pelo viés da EPP é educar para a argumentação, uma vez que, ao promover a construção de novos argumentos, se logra atingir as esferas dos pilares específicos da educação: o ser, o fazer e o conhecer. Assim, em busca de práticas pedagógicas que culminem nessa ação, temos o seguinte como problema de pesquisa para este manuscrito: quais são as percepções e análises atribuídas a uma Sequência Didática (SD) proposta como prática pedagógica para a interface entre argumentação científica (AC) e Educação pela Pesquisa (EPP)? Esta é uma pesquisa caracterizada como sendo qualitativa do tipo pesquisa participante. No que se refere às questões metodológicas, os participantes, pós-graduandos de um curso de especialização em Ensino de Ciências, após uma formação EaD via Blog, analisaram e emitiram o seu parecer e suas considerações a uma Sequência Didática criada com o objetivo de promover a construção do conhecimento científico por intermédio de uma prática que funde a perspectiva da AC e da EPP. Esses pareceres e considerações foram analisados à luz da Análise de conteúdo. Dos resultados obtidos, emergiram as seguintes categorias de análise: Complementariedade entre AC e EPP e Maturidade cognitiva. Os resultados revelaram que a SD construída é apropriada e uma estratégia pedagógica frutífera para a construção do conhecimento científico.

Palavras chave: argumentação científica; educação pela pesquisa; sequência didática; prática pedagógica.

\section{Abstract}

The present article shows as a main scope the interface between the Scientific Argumentation and Teaching Thru Research (TTR). It's known that teaching is a wide practice and to promote this teaching thru the TTR view is to teach the argumentation, once, by promoting the construction of new arguments, it's possible to achieve the pillar spheres of the teaching: to be, to do and to know. This way, in search of the pedagogical practices that result in this action, we have the following as the issue for the research of this

\footnotetext{
${ }^{1}$ Pontifícia Universidade Católica de Campinas | rpezarini@gmail.com

2 Pontifícia Universidade Católica de Campinas | samuelms@gmail.com
} 
manuscript: what are the perceptions and analysis given to a Teaching Sequence (TS) proposed as pedagogical practice to the interface between the Scientific Argumentation (SA) and Teaching Thru Research (TTR). This is a research featured as being qualitative of the participant research kind. As it refers to methodological questions, the participants, postgraduation students of a course specialized in Science Teaching, after a DL (Distance Learning) graduation thru Blog, analyzed and issued their opinion and considerations to a Teaching Sequence (TS), created with the objective to promote the construction of the scientific knowledge by a practice that melts the SA and the TTP perspective. These opinions and considerations were analyzed by the content analysis. From the obtained results, emerged the following analysis categories: complementarity between SA and TTP and cognitive maturity. The results revealed that the TS built is appropriated and a fruitful pedagogical strategy for the building of the scientific knowledge.

Keywords: scientific argumentation; teaching thru research; teaching sequence; pedagogical practices.

\section{Introdução}

É possível idealizar uma metodologia de ensino que se paute nos princípios da Educação pela Pesquisa (EPP) tendo como foco central a Argumentação Científica (AC)? A resposta a essa indagação nos remete a pensar em que processo de ensino-aprendizagem consideramos adequado e almejamos e, de imediato, se faz necessário anunciarmos que, no atual panorama, a educação anseia por um ensino que seja pautado na perspectiva da ação de construção do conhecimento contínuo, como aponta Becker (1993, p. 88):

[...] o conhecimento não é dado, em nenhuma instância, como algo terminado. Ele se constitui pela interação do indivíduo com o meio físico e social, com o simbolismo humano, com o mundo das relações sociais; e se constitui por força de sua ação, e não, por qualquer dotação prévia na bagagem hereditária ou no meio.

A interface entre a AC e a EPP se faz possível, pois a perspectiva da EPP como elemento intrínseco à construção da habilidade argumentativa pode ser considerada a ação mais adequada para o contexto escolar, mas advertem Borges e Lima (2020, p. 13) que é preciso que, em consequência dessa complementariedade que os envolvidos, "[...] em função disso, assumam explicitamente essa vinculação, fundamentando-a e, como consequência disso, fortalecendo-a.".

Quanto às especificidades e pontualidade, cada uma dessas vertentes confere ao processo de construção do conhecimento amplas possibilidades. Podemos considerar que as pesquisas no Ensino de Ciências (EC) elucidam que a AC é uma metodologia frutífera para o desenvolvimento do pensamento crítico e da alfabetização científica (JIMENEZALEIXANDRE, 2010).

Para a EPP, as especificidades promovem um compartilhamento para com a perspectiva da AC, já que suas ações se pautam em questionar, argumentar e escrever. No entanto é preciso que as práticas escolares conduzam o estudante a tais ações, como salienta Lima (2004, p. 81): "[...] espaços efetivos para o aluno questionar, argumentar e escrever, entrelaçando conteúdos escolares e realidade, num processo que tem no diálogo 
o elemento integrador.". Ou seja, um processo que demanda ações conjuntas entre o docente no papel de condutor/orientador e o estudante no papel de construtor/realizador.

Essa perspectiva é a de que as ações para com a EPP são de envolvimento entre docente e estudante, como apontam Moraes, Galiazzi e Ramos (2002, p. 10), quando descrevem que:

[...] uma das maneiras de envolver os sujeitos, alunos e professores, num processo de questionamento do discurso, das verdades implícitas e explícitas nas formações discursivas propiciando, a partir disso, a construção de argumentos que levem a novas verdades [...]. Envolver-se nesse processo é acreditar que a realidade não está pronta, mas que se constitui a partir de uma construção humana.

Contudo é notória a interface e a possibilidade de que a perspectiva da EPP seja facilitadora e promovedora da construção da habilidade argumentativa e, com isso, podemos pensar e idealizar um EC que se distancie da perspectiva livresca e tradicional, mas se apoie em um ensino coeso que acreditamos que a prática da EPP como facilitadora da argumentação científica pode ser uma metodologia frutífera, para que, segundo Krasilchik e Marandino (2007, p. 53), esse ensino possa "[...] estimular a atividade intelectual e social dos alunos, motivar e dar prazer pelo aprendizado, fazer com que os alunos conheçam fatos, conceitos e ideias básicas da ciência.".

Enfim, por acreditar que, quando a perspectiva da EPP é colocada em prática, essa se constitui como elemento engajador e possibilitador da AC e tal interface se caracteriza como sendo uma ação possibilitadora da ativa construção do conhecimento por parte dos estudantes em processo de formação, uma vez que agem de forma a elaborar e reconstruir seus argumentos para ações e fenômenos em uma ação que, por sua vez, é mediada pelo professor, quando suas ações se pautam na ideologia de que devemos educar pela pesquisa (BORGES; LIMA, 2020).

Contudo é em busca de respostas para ratificar ou rechaçar a ideologia de que a EPP é facilitadora da AC que este manuscrito se pauta na seguinte questão problema: quais são as percepções e análises atribuídas a uma Sequência Didática (SD) proposta como prática pedagógica para a interface entre argumentação científica (AC) e Educação pela Pesquisa $($ EPP)?

\section{Referencial teórico}

Em que a prática do ensino contemporâneo deve se pautar? Qual perspectiva e objetivo deve ser almejado para um ensino que seja de fato possibilitador da construção do conhecimento? Tais indagações são relevantes e impulsionam ações e atitudes em prol de um ensino com tais especificidades. Da mesma forma, nos remete a pensar nos meios e nas metodologias que possam ser possibilitadoras dessas ações.

De imediato, ao idealizar um ensino com essas características, vislumbramos ações que possam promover uma educação que se paute na construção do conhecimento, tendo como objetivo a perspectiva da EPP, para que essa possa ser base para as práticas e todo o processo de ensino e aprendizagem, de forma a conduzir suas ações por intermédio da construção e de argumentos. 
De forma bem pontual, é possível afirmar que a prática da AC se relaciona à perspectiva do viés da EPP, sendo essa prática considerada imprescindível para a construção do conhecimento.

Quando tratamos da perspectiva do ensino pelo viés da argumentação, entendemos que essa deve ser entendida como "[...] a capacidade de relacionar dados e conclusões, de avaliar enunciados teóricos à luz dos dados empíricos ou procedentes de outras fontes." (JIMÉNEZ-ALEIXANDRE; DÍAZ DE BUSTAMANTE, 2003, p. 360).

Tendo vislumbrado esse conceito para a $A C$, entendemos que sua prática em sala de aula requer um meio ou mecanismo que possa conduzir os estudantes a construção da AC. As pesquisas voltadas para essa esfera nos relevam que sim, há um padrão com efetiva utilização, quando a proposta de ensino se pauta por esse prisma, sendo ele o Padrão de Toulmin, como salientam Pezarini e Maciel (2018, p. 68), é "O padrão de maior ênfase para as pesquisas em Argumentação no Ensino de Ciências é o TAP, Padrão de Toulmin. Nesse caso, Stephen Toulmin (2006) propõe uma abordagem estrutural dos elementos constitutivos do raciocínio argumentativo.".

A pesquisa em desenvolvimento que dá origem a este manuscrito adota como mecanismo de condução para a construção da AC um Modelo Didático Misto (MDM), sendo ele produto da fusão do referido Padrão de Toulmin (2006) com a perspectiva das sequências narrativa e explicativa de Bonini (2007).

Em linhas gerais, o referido MDM é composto pelos seis elementos do Padrão de Toulmin (2006), quais sejam: conclusão (C) - que pode ser confirmada por um dado (D), autorizado por uma lei de passagem $(G)$, que é retirada de uma base de apoio (A). A refutação $(R)$ é a forma de invalidar essa passagem, como mostra a Figura 1, a seguir, tendo por sua vez a fusão das sequências narrativa e explicativa de Bonini (2007).

$\mathrm{D}$
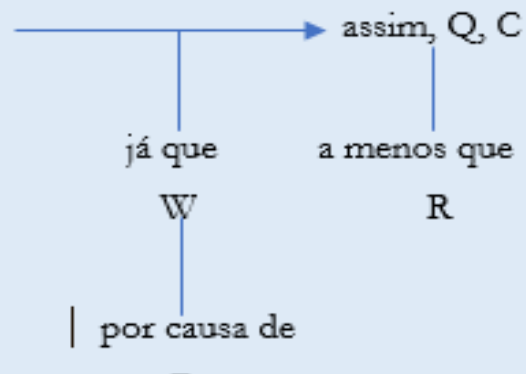

$\mathrm{R}$

Figura 1: Esquema do Padrão de Argumento de Toulmin. Fonte: Toulmin (2006, p. 150).

Adotar as sequências narrativa e explicativa de Bonini (2007) se justifica por acreditar que as especificidades dos elementos de conclusão e de refutação são para os estudantes dependentes de apoio para a sua execução. Ademais, corroboram com essa decisão as perspectivas de Jimenez-Aleixandre e Brocos (2015) e a de Vieira et al. (2015). Para o elemento da conclusão, Jiménez-Aleixandre e Brocos (2015, p. 148) ensinam que "[...] um tipo particular de conclusões são as explicações".

Para Vieira et al. (2015, p. 718), é um ato de "[...] levantar um problema, resolvê-lo de forma detalhada e, finalmente, sumarizar a resposta para (re)avaliar o problema.".

Quanto à adoção da sequência narrativa para a refutação, segundo Jiménez-Aleixandre e Brocos (2015, p. 149), essa apresenta algumas particularidades à luz de Toulmin (1958): "[...] é o reconhecimento das restrições ou exceções à conclusão.". 
Segundo Vieira et al. (2015, p. 716), "[...] descrição narrativa. O desencadeamento 1 é o momento em que ocorre um fato que quebra a ordem estabelecida, gerando assim ações (reações e/ou avaliação)."

Assim, fica evidente que a fusão dos referidos protótipos de Toulmin (2006) e de Bonini (2007) são complementares e apoiam a construção da argumentação, cuja estrutura compõem o MDM, conforme representando na Figura 2, a seguir.

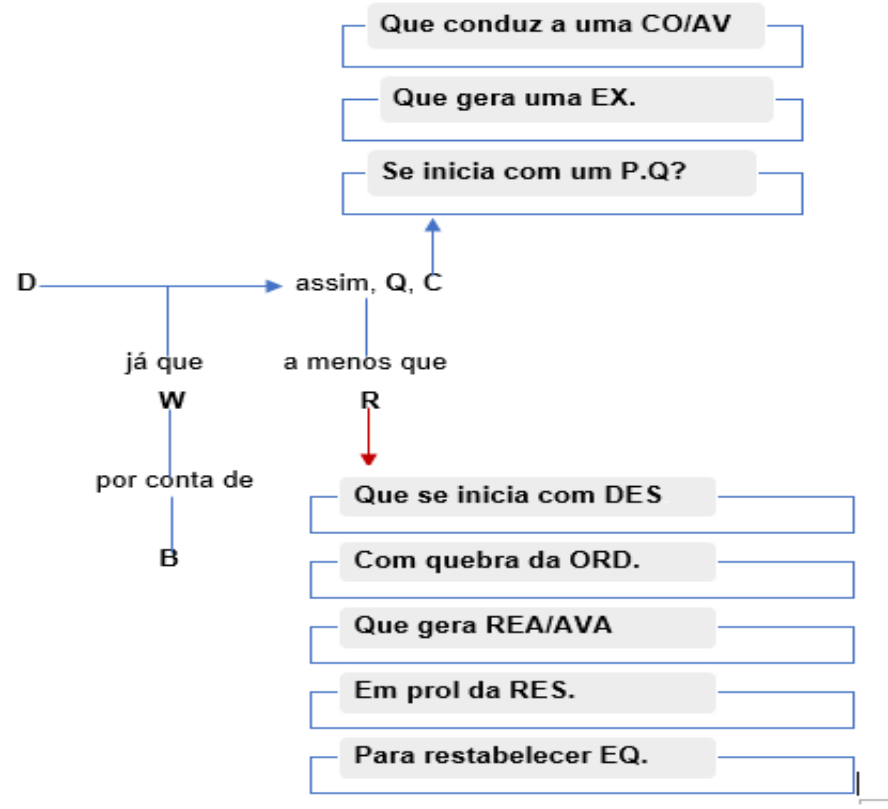

Figura 2: O Modelo Didático Misto. Fonte: $\mathrm{O}$ autor.

A AC é uma temática, é uma prática apropriada para a construção do conhecimento científico, pois consegue estar para além da ratificação de um conhecimento, uma vez que se volta a práticas singulares como produção, comunicação e avaliação de um conhecimento que é posto em evidência, como deixa evidente Gregory Kelly (2008, p. 99), quando explica que:

Os jeitos específicos pelos quais os membros de uma comunidade propõem, justificam, avaliam e legitimam enunciados de conhecimento dentro de um determinado contexto disciplinar [...] um aspecto importante da participação na ciência é a aprendizagem das práticas epistêmicas associadas à produção, à comunicação e à avaliação de conhecimento.

Construir o conhecimento é a ação primeira e o objetivo de um docente e podemos dizer que as ações discursivas e os momentos de instigação e discussão em sala de aula são precursores dessa construção. Ademais, agir por intermédio das discussões em sala com o propósito de construir o conhecimento traz consigo a perspectiva da argumentação e tal prática faz emergir novos conceitos e conhecimentos.

Sasseron (2015, p. 60) afirma que há essa peculiaridade nas práticas discursivas promotoras da argumentação e considera que "[...] As interações discursivas são promotoras do processo argumentativo, mas, ao mesmo tempo, fomentam as argumentações e colaboram para que sejam mais extensas e ricas em dimensões em análise.". 
De forma afirmativa, podemos dizer que a AC é essencial para o processo de construção do conhecimento, dada a sua amplitude e magnitude dentro desse processo.

Sasseron (2015), apoiando-se em Leitão (2011), corrobora com essa perspectiva ao ensinar que

A argumentação, no contexto do ensino, evidencia tanto aspectos vinculados ao raciocínio prático, quanto ao raciocínio teórico, aproximando alunos não apenas de conceitos, leis e teorias das ciências, mas também, de processos e características da construção do conhecimento. (SASSERON, 2015, p. 60)

Enaltecemos ao longo das discussões até o momento que a AC possui, graças a sua essência, a prática discursiva. Assim, por esta pesquisa tratar da interface entre as perspectivas da AC e da EPP, salientamos o quanto essas estão relacionadas e justificamos a necessidade de que suas práticas sejam conjuntas pelo fato de que a ideologia da EPP prega a relação didático-discursiva entre os envolvidos.

Moraes, Galiazzi e Ramos (2002, p. 10) deixam clara essa prática conjunta entre docente e discente para a construção do conhecimento, não sendo, portanto, uma prática em que o docente regente é o detentor e disseminador do conhecimento já pronto. Desse modo, os autores enfatizam que a perspectiva da EPP está nas ações de questionamento, avaliação e argumentação.

[...] uma das maneiras de envolver os sujeitos, alunos e professores, num processo de questionamento do discurso, das verdades implícitas e explícitas nas formações discursivas, propiciando, a partir disso, a construção de argumentos que levem a novas verdades [...]. Envolver-se nesse processo é acreditar que a realidade não está pronta, mas que se constitui a partir de uma construção humana.

Vislumbramos, portanto, que a identidade da EPP está intrínseca ao processo e à perspectiva da AC. Assim, por considerar que a perspectiva da prática da EPP pode contribuir ricamente com o desenvolvimento da AC em sala de aula (RAMOS, 2000), adotamos como prática pedagógica uma Sequência Didática (SD) que se pauta na fusão das perspectivas da EPP e da AC.

É, contudo, por meio dessa SD que intencionamos desenvolver uma prática pedagógica que vise à amplitude da construção do conhecimento, com o objetivo de desenvolver os pilares da Educação, dentre eles o ser, o fazer e o conhecer.

Enfim, a singularidade dessa pesquisa em desenvolvimento nos remete a uma prática em que a $A C$, se pautando na perspectiva da EPP, é condizente e possibilitadora do desenvolvimento desses patamares.

Moraes; Galiazzi e Ramos (2002. p. 16) ensinam que "[...] é fundamental pôr em movimento todo um conjunto de ações, de construção de argumentos que possibilitem superar o estado atual e atingir novos patamares do ser, do fazer e do conhecer.".

\section{Percurso metodológico}

De forma a caracterizar esta pesquisa, no que se refere às questões metodológicas, essa se define como sendo de ordem qualitativa. 
Demo (2011) salienta que, nesse tipo de pesquisa, é possível reconstruir teorias, bem como, realizar e/ou promover a discussão de fatos ou fenômenos da realidade.

A realidade posta em evidência nesta pesquisa é a percepção e a análise a uma SD proposta como prática pedagógica da interface entre a AC e a EPP. Vale salientar que se trata do segundo momento de uma Pesquisa Participante (PP), realizada com professores da educação básica e pós-graduandos de um curso de Pós-graduação Lato-sensu em Ensino de Ciências (EC), que são caracterizados no Quadro 1, a seguir.

\begin{tabular}{|c|c|c|c|c|c|c|}
\hline \multicolumn{7}{|l|}{ Idade } \\
\hline \multicolumn{2}{|c|}{$\begin{array}{l}\text { Entre } 20 \text { e } 30 \text { anos } \\
8,3 \% \text { (1) }\end{array}$} & \multicolumn{2}{|c|}{$\begin{array}{l}\text { Entre } 31 \text { e } 40 \text { anos } \\
33,33 \% \text { (4) }\end{array}$} & \multicolumn{2}{|c|}{$\begin{array}{l}\text { Entre } 41 \text { e } 50 \text { anos } \\
41,7 \%(5)\end{array}$} & $\begin{array}{l}\text { Entre } 51 \text { e } 60 \text { anos } \\
16,7 \% \text { (2) }\end{array}$ \\
\hline \multicolumn{7}{|c|}{ Cidade/Estado onde reside } \\
\hline \multicolumn{2}{|c|}{$\begin{array}{l}\text { São Paulo } \\
3 \text { participantes } \\
\text { Volta Redonda }\end{array}$} & \multicolumn{2}{|c|}{$\begin{array}{l}\text { Florianópolis } \\
1 \text { participante } \\
\text { São Bernardo do } \\
\text { Campo }\end{array}$} & $\begin{array}{l}\text { Goiâr } \\
1 \text { par } \\
\text { Camr } \\
4 \text { par }\end{array}$ & $\begin{array}{l}\text { ante } \\
\text { Is } \\
\text { pantes }\end{array}$ & $\begin{array}{l}\text { Itapetininga } \\
1 \text { participante }\end{array}$ \\
\hline \multicolumn{7}{|c|}{\begin{tabular}{l|l|l}
1 participante & 1 participante & 4 pa \\
Em qual(is) ciclo(s) da educação você leciona?
\end{tabular}} \\
\hline $\begin{array}{l}\text { Anos Iniciais EF } \\
16,7 \%(2)\end{array}$ & \multicolumn{2}{|c|}{ Anos Finais EF } & \multicolumn{2}{|c|}{ Ensino Médio } & $\begin{array}{l}\text { Anos Finais e } \\
\text { Ensino Médio }\end{array}$ & $\begin{array}{l}\text { Ensino Superior } \\
8,3 \% \text { (1) }\end{array}$ \\
\hline \multicolumn{7}{|c|}{ Formação/graduação dos cursistas participantes } \\
\hline \multicolumn{7}{|c|}{ Tipo de IES (Instituição de Ensino Superior) do curso de graduação } \\
\hline \multicolumn{3}{|c|}{$\begin{array}{l}\text { Estadual } \\
25 \%(3)\end{array}$} & \multicolumn{3}{|c|}{$\begin{array}{l}\text { Federal } \\
16,7 \%(2)\end{array}$} & $\begin{array}{l}\text { Privada } \\
58,3 \%(7)\end{array}$ \\
\hline
\end{tabular}

Quadro 1: Caracterização dos participantes.

Em linhas gerais, a PP é aquela em que o participante exerce o controle sobre a produção do conhecimento em foco. Desse modo, a essência desta pesquisa está em ações específicas e pontuais no contexto de que o pesquisado é parte integrante da pesquisa. Ou seja, a PP confere aos sujeitos ações pontuais que se distanciam do rigor científico, como descreve Méksenas (2007, p. 2). "[...] pensar, lembrar, relacionar fatos e conscientizar-se, mesmo que essa tomada de consciência seja algo provisório e a ser questionado no futuro.".

Há pesquisadores que acreditam que a PP seja classificada como sendo uma estratégia que se distancia do rigor metodológico científico, fato esse que não é verdade, como aponta Demo (2008, p. 8), quando afirma que:

Pesquisa Participante produz conhecimento politicamente engajado. Não despreza a metodologia cientifica em nenhum momento no sentido dos rigores metódicos, controle intersubjetivo, discutibilidade aberta e irrestrita, mas acrescenta o compromisso com mudanças concretas, em particular voltadas para os marginalizados.

A Pesquisa Participante permite o acesso ao saber, onde os paradigmas de dominância da pesquisa em si são deixados de lado, como aponta Tandon (1981, p. 21), ao postular que:

A essência do nosso argumento é que a PP é uma tentativa de instituir alternativas ao paradigma dominante de pesquisa, bem como, de providenciar acesso ao saber por parte dos marginalizados. É essa dupla 
ênfase na PP que a distingue de outras modas e a torna mais que um conjunto de novas técnicas.

Os estudantes em questão participaram de uma formação via EaD. Como parte dessa formação, consta um link do Google forms para a avaliação da SD ${ }^{3}$, o qual deveria apontar questões relacionadas a aplicabilidade, coerência, pertinência e adequação dessa SD, tal como descritas no Apendice.

Os participantes desta pesquisa analisaram a referida SD descrita no Quadro 2, de modo a exaurir todas as possibilidades para se chegar à conclusão de sua adequação ou não adequação como prática pedagógica.

As abordagens dos participantes desta pesquisa foram analisadas pelo método da Análise de Conteúdo de Bardin (2006). A Análise de Conteúdo de Bardin (2006) possui características singulares: objetividade, sistematização e forma quantitativa, manifestada em uma comunicação.

De acordo com Silva et al. (2017), essa ação se refere a um conjunto de técnicas que utilizam procedimentos sistemáticos para analisar o conjunto de informações.

De modo bem pontual e de caracterização da ação e dos procedimentos da análise de conteúdo proposta por Bardin (2006), fica evidente que ela tem como propósito realizar uma análise de conteúdo em busca de questões específicas que revelem explicitação, sistematização e expressão do conteúdo de mensagens. Bardin (2006) aponta que tal ação é possivel a partir de outras ações compostas em três fases, a saber: a) pré-análise; b) exploração do material; e c) tratamento dos resultados, inferência e interpretação.

A primeira fase desse processo é realizada por quatro ocorrências distintas, nas quais são realizadas as seguintes ações: leitura flutuante, que permite e possibilita o primeiro contato com o material e, a partir dela, é possível selecionar/escolher documentos e/ou informações a serem analisadas e, de posse delas, promover o recorte desses documentos para a formulação de hipóteses, que serão verificadas para a elaboração dos indicadores.

Bardin (2006) explica que, quando se procede com a seleção dos documentos a serem analisados, uma série de ações e procedimentos devem obedecer a estes critérios: exaustividade da totalidade da comunicação; representatividade, segundo a qual os documentos devem representar de fato o universo pesquisado; homogeneidade no que se refere ao fato de os dados tratarem do mesmo tema; e pertinência dos documentos que devem condizer com os objetivos da pesquisa.

A categorização é a fase seguinte do processo de análise prescrito por Bardin (2006), a chamada segunda fase. Para a terceira fase, as ações se voltam para o tratamento dos resultados, que devem culminar em uma análise reflexiva e crítica.

Especificamente para esta pesquisa, a análise de conteúdo na perspectiva adotada é desenvolvida a partir da coleta dos dados que, inicialmente, parte de uma leitura flutuante, a fim de identificar as respostas e seus eixos de maior predominância. Assim, é possível separar os elementos com maior evidência nas respostas. Após essa fase, com a leitura intensa e exaustiva das respostas de maior evidência, surgem as categorias de análise que, posteriormente são analisadas e discutidas a partir de referências que dialogam sobre tais categorias.

\footnotetext{
${ }^{3}$ Disponível em: https://forms.gle/LsuFXegqyweaRAGa8
} 
As respostas elaboradas pelos participantes a cada questão instigadora e norteadora da avaliação, do parecer e das considerações à SD foram compiladas na íntegra. Vale ressaltar que, dos vinte e cinco cursistas/participantes, quatro desistiram do curso por questões pessoais e diversas e, sendo a pesquisa não obrigatória, mas sim, voluntária, doze se prontificaram a participar.

Como descreve a ação da AC de Bardin (2006), a primeira ação foi a leitura flutuante do material que permitiu a seleção de informações pertinentes que se converteram em um recorte de representatividade do universo da pesquisa, ao trazer informações peculiares e homogêneas da pesquisa em si. Para caracterizar essa seleção, adotamos como princípio a seleção de seis das doze respostas obtidas para serem base para a categorização e, sendo essas as que são compiladas para este manuscrito.

\section{Resultados e discussões}

É possível afirmar que um dos elementos que constituem a singularidade deste manuscrito está na transcrição das avaliações e/ou pareceres emitidos pelos docentes participantes para a SD, construída como parte integrante do curso de formação em EaD.

A riqueza deste material está para além da simples constatação da pertinência e eficiência dos elementos constituintes desta SD, mas sim, caracteriza de forma a ratificar ou conduzir a retificações de uma prática pedagógica que promova a interface entre práticas e/ou metodologias de ensino que culminem na construção de um EC sólido e coeso.

A análise da SD em questão, segundo nossa concepção, requer em primeira mão a constatação do nível de conhecimento dos docentes participantes sobre a prática pedagógica da AC e da EPP. Assim, perguntamos aos participantes: Qual é a sua concepção sobre a prática pedagógica da Argumentação Científica (AC) aliada à Educação pela Pesquisa (EPP) em sala de aula?

Em resposta a esse primeiro questionamento, os participantes apontam que a interface entre os princípios da AC e da EPP se complementam e que, de fato, enaltecem a ratificação da construção do conhecimento científico, como pode ser observado nas transcrições das respostas selecionadas.

Acredito ser boa, tudo dependerá da clientela e da motivação

Poder atribuir o científico ao real, mundos que estão tão distantes.

Muito importante, pois o aluno aprende praticando e vendo sentido no que está aprendendo.

Não conhecia o método adotado. À primeira vista, parece ser bem complexo, mas, ao analisar o significado das siglas e entender a prática como um processo de construção, achei muito interessante e válido para o ensino-aprendizado.

São ações que se complementam. Penso que a perspectiva da Educação pela Pesquisa, por requerer a prática da argumentação, consegue promover o desenvolvimento de ambas as habilidades.

Acredito que a argumentação científica é uma das mais importantes ferramentas usadas na Educação pela Pesquisa. De nada vale uma pesquisa realizada por um aluno, se ele não for capaz de transformar o conhecimento obtido em elemento de argumentação, justificando ou 
refutando uma determinada hipótese para explicar determinando fenômeno.

É possível constatar que, na visão dos docentes participantes, a prática pedagógica, a partir da interface entre a perspectiva da AC e da EPP, é de fato uma ação possibilitadora do conhecimento.

Podemos estabelecer um paralelo entre a identidade da SD analisada com a perspectiva do pensamento de Chassot (2003), quando esse pesquisador faz seus apontamentos de modo a evidenciar que a alfabetização científica, ou seja, as premissas para se conseguir desenvolver a alfabetização científica está em consonância com aquelas que integram a interface entre a AC e a EPP que regem essa SD.

Por assim pensarmos, buscamos identificar que essa análise está para além da nossa concepção e, desse modo, questionamos os participantes sobre esse ponto específico: A prática pedagógica pela argumentação científica (AC) e pela Educação pela Pesquisa (EPP) visa à alfabetização científica. Assim, a sequência didática desenvolvida em sua perspectiva está em consonância com o viés de Chassot (2003).

Parece que se fará Alfabetização Científica quando o Ensino de Ciências contribuir para a compreensão de conhecimentos, procedimentos e valores que permitam aos estudantes tomarem decisões e perceberem tanto as muitas utilidades da ciência e suas aplicações na melhoria da qualidade de vida, quanto a limitações e consequências negativas de seu desenvolvimento (CHASSOT, 2003, p. 99).

Em resposta a esse questionamento, os cursistas afirmaram que:

Concordo plenamente com Chassot (2003), sem perceber a utilidade do conhecimento, não tem sentido prático nos conteúdos oferecidos pela escola.

Podendo de forma harmoniosa buscar um conhecimento dinâmico.

A alfabetização científica, com certeza, contribui para o conhecimento do estudante.

Exatamente. De acordo com minha concepção, o ensino de Ciências permite aos estudantes a significação do nosso papel no mundo e das relações que aqui mantemos.

Concordo. De fato, o ensino de ciências precisa se apoiar e amparar suas ações e objetivos dentro do propósito de uma educação que promova a melhoria na qualidade de vida; que o estudante possa ter a habilidade de se posicionar e ser hábil na tomada de decisões.

De fato, ao compreender os mecanismos que promovem o avanço da ciência e como esse processo é permeado não somente de coleta de dados, mas também por discussões e mesmo disputas, os alunos começam a ter maior noção da complexidade do processo, ao mesmo tempo de podem passar a ver o desenvolvimento da ciência de forma mais humanizada.

Quando voltamos o nosso olhar às especificidades de composição e/ou construção dessa SD, composta pelo MDM citado e pela perspectiva da EPP (questionamento, argumentação e validação), se faz necessário identificar se ela apresenta um grau de complexidade que esteja para além dos conhecimentos desses docentes. 
Eis os questionamentos feitos aos participantes: A perspectiva adotada nesta Sequência Didática (SD) ocorre por meio de um Modelo Didático Misto (Padrão de Toulmin + Perspectiva de Bonini). Essa perspectiva, na sua concepção, se mostra com que grau de complexidade para você, como docente, executá-la em suas aulas? Em resposta, obtivemos que, para $50 \%$ dos participantes, a SD é complexa, ao passo que, para os outros $50 \%$ dos participantes, ela é parcialmente complexa.

Tendo identificado qual é o nível de complexidade que os docentes atribuem a essa SD quanto a seus próprios conhecimentos, eles nos indagaram sobre o grau de complexidade da SD na visão deles, para a prática junto aos estudantes.

Assim, perguntamos aos participantes: A perspectiva adotada nesta Sequência Didática (SD) acontece por meio de um Modelo Didático Misto (Padrão de Toulmin + Perspectiva de Bonini). Essa perspectiva, na sua concepção, se mostra com que grau de complexidade para os seus alunos? Em resposta, obtivemos que, para 16,7\% (1 participante), é muito complexa; ao passo que, para 16,7\% (1 participante), ela é parcialmente complexa para ser aplicada aos seus alunos; e, para 66,7\% (4 participantes), esta SD é complexa para seus alunos.

Quando idealizamos uma SD, um dos primeiros pontos a serem considerados é a qual ciclo de ensino se destina a aula, assim, consideramos como sendo essencial a constatação da adequação dessa SD para o ciclo de ensino. Logo, perguntamos aos cursistas: Essa SD, com essa perspectiva, é adequada a qual ciclo de ensino na sua visão? Em resposta a esta indagação obtivemos:

Ensino médio $2^{\circ}$ e $3^{\circ}$ anos, dependendo da clientela.

Ensino médio.

Ensino fundamental, anos finais.

Acredito serem adequadas nos últimos anos do ensino fundamental II.

Anos Finais no $9^{\circ}$ ano, mas acredito ser mais adequada para o Ensino Médio. Isso de acordo com o perfil dos alunos que possuo atualmente.

Acredito que os alunos no Ensino Fundamental 2, em especial no $8^{\circ}$ ano, tem boas condições de realizar a SD.

Como constatado, houve concordância de que essa SD é pertinente, tanto para o Ensino Fundamental Anos Finais, quanto para o Ensino Médio. Tais constatações ainda são justificadas pelos participantes quando perguntamos a eles: qual é a justificativa que você apresenta para afirmar que esta SD é adequada para o(s) ciclo(s) que você indicou?

A SD precisa ou requer certa maturidade de raciocínio dos estudantes e, por isso, acredito que, nas duas últimas séries do ensino médio, seja o mais adequado.

Necessário um melhor desenvolvimento técnico.

Devidos aos conhecimentos prévios dos estudantes.

A justificativa é o nível de complexidade. Os alunos mais novos podem ter dificuldade em estabelecer as relações.

Os estudantes da rede Estadual de São Paulo, falo pelos estudantes que possuo atualmente. são carentes da habilidade argumentativa e das práticas e ações da educação pela pesquisa. No ensino médio. apesar de ainda terem essa carência, a maturidade que já possuem, ou ao menos 
deveriam ter, permite que a aula - por ser complexa para eles - possa ser trabalhada pelo professor com mais afinco.

O fato de os alunos já terem uma maturidade maior, não só em termos de repertório conceitual, mas mesmo de socialização e compartilhamento de informações. Além do mais, no $8^{\circ}$. ano geralmente, é ministrado o conteúdo que se refere ao corpo humano e os sistemas biológicos. Dessa forma, o tema da vacinação se encaixa perfeitamente com os tópicos analisados.

As justificativas para considerar adequada para determinado ciclo de ensino segundo os participantes, é o fato de que é preciso maturidade dos alunos e preparação/formação dos docentes.

Tendo constatado o nível de complexidade da SD para os docentes regentes e para os discentes, perguntamos sobre a avaliação geral dessa aos participantes: Em linhas gerais, qual é a sua avaliação sobre esta SD? Nesse caso, as avaliações dos participantes para essa SD se mostraram positivas, como pode ser verificado nas transcrições abaixo:

Achei interessante, criativa nas estratégias e possível de se aplicar.

Bem direta e didática.

Muito boa.

A sequência didática permite o alcance dos objetivos esperados e um excelente exemplo de ensino por investigação.

Eficiente. Ela consegue de fato estabelecer um vínculo entre a educação pela pesquisa e a argumentação. Acredito que, pela argumentação, conseguimos desenvolver em nossos alunos a ideologia do pensamento crítico que é extremamente válido para a alfabetização científica

Pessoalmente achei muito interessante, mas ao mesmo tempo, acredito que os alunos precisam de uma grande maturidade cognitiva para conseguir sistematizar ativamente todas as etapas da sequência. Dessa forma, os alunos precisam já estar acostumados de certa forma com esse tipo de atividade para obter resultados significativos, ao invés da mera replicação do que eles acreditam ser uma "resposta certa".

Para além da constatação da avaliação de uma SD, pensamos que fazem parte dessa análise outros aspectos que agregam à veracidade e à composição de sua efetividade como proposta pedagógica. Assim, perguntamos aos participantes: qual é o seu parecer para esta Sequência Didática (Coerência, pertinência, adequação, suficiência etc.)? Em linhas gerais, foi possível classificar a SD como sendo coerente, adequada e pertinente, como pode ser identificado nas transcrições a seguir:

Achei boa a sequência didática.

Coerência.

Coerência.

Pertinência. A proposta é pertinente e contribui para a construção do conhecimento.

Acredito que seja uma sequência didática coerente e adequada para o propósito da construção do conhecimento científico pelo viés da 
educação pela pesquisa e da argumentação. Requer um pré-preparo dos estudantes dadas as carências que eles possuem.

Ainda mais no contexto da pandemia atual, o tema não poderia ser mais pertinente. A sequência é bastante interessante, mas, ao mesmo tempo, sinto que o número de aulas que a sequência demanda não são facilmente encaixados no planejamento das aulas.

As respostas às questões iniciais feitas aos participantes como análise da SD em questão evidenciaram a ratificação da qualidade e pertinência dessa para com o objetivo a que ela se propõe. No entanto, mesmo diante desse quadro positivo, perguntamos se a referida SD carece de mudanças: Quais adaptações você faria nesta SD? O único aspecto apontado como retificação está no tempo destinado ao desenvolvimento das atividades, como é possível constatar nas respostas dos participantes.

Não realizaria nenhuma mudança.

Focaria na dinâmico, e o conhecimento superficial.

Nenhuma, está perfeito.

Nenhuma adaptação, porém é necessário estudo do docente antes de aplicar.

Nenhuma adaptação.

Tendo em vista as imposições da sequência do material didático, as 3 aulas necessárias para realizar a SD podem não ser exatamente muito facilmente encaixadas na sequência das aulas, tendo em vista os tópicos considerados "prioritários" no espaço escolar. Acho que seria interessante, mesmo não sendo a opção ideal, de propor uma versão simplificada da atividade também, podendo ser aplicada em 1 ou 2 aulas.

Tendo a concepção do parecer do quão essa SD é coerente e pertinente por parte dos cursistas, no entanto cabe ainda indagar sobre a relação entre as especificidades dessa e da receptividade e desenvoltura dos estudantes para com ela. Assim, perguntamos aos cursistas: para que a aplicação dessa SD fosse possível em suas aulas, algo deveria ser adaptado? Seus atuais estudantes possuem as habilidades suficientemente desenvolvidas para acompanhar o viés da argumentação científica e da Educação pela Pesquisa contidas neste instrumento? Em respostas a esta indagação, obtivemos as seguintes afirmações e/ou constatações:

Acredito que não, estamos há 18 meses fora da sala de aula com atividades online. Estamos muito distantes da real situação pedagógica desse aluno quanto a suas habilidades e competências.

É bem desenvolvido.

Não, alguns estudantes teriam dificuldade.

Não. Acredito que os alunos do $8^{\circ}$ e $9^{\circ}$ ano consigam acompanhar o que foi proposto.

A Sequência não requer mudança. O que é preciso é preparar os estudantes antes da execução dessa sequência didática, pois existem fragilidades nos estudantes para que possam acompanhar. 
Acredito que eles têm capacidade de realizar a SD, mas não chega a ser uma atividade fácil. A capacidade de argumentar cientificamente é uma habilidade que depende de prática e é muito possível que alguns dos meus alunos teriam muita dificuldade em desenvolver uma argumentação robusta.

Para finalizar as avaliações desta SD como instrumento pedagógico, questionamos aos participantes sobre os aspectos relacionados a sua construção em fases e/ou momentos. Com isso, perguntamos a eles: A Sequência Didática (SD) apresentada está dividida em três momentos ou fases. Na sua concepção, os objetivos dessa SD são passíveis de serem alcançados com essa divisão e tempo/duração? Como você avalia a construção de cada uma dessas fases?

Dentro da perspectiva prevista, acredito que está coerente e boa. Mas acredito que os alunos apresentarão dificuldades de entendimento do que está sendo proposto, pois antes da pandemia, já apresentavam defasagem pedagógica e agora com esse período longo de fora da escola só aumentou a defasagem.

Sim. Acredito que os alunos podem ter dificuldade, mas com a orientação e acompanhamento corretos, o objetivo pode ser alcançado. Esse Modelo Didático Misto para os meus estudantes o vejo complexo. Eles não conhecem essa prática e se fará necessária uma pré-discussão e formação com eles, em especial, para dar ênfase ao fato de que a argumentação científica possui elementos distintos para a sua construção.

Avalio de forma positiva, pois ela faz promover, sim, a construção do conhecimento. O meu único apontamento seria a dificuldade de alguns estudantes, principalmente ao retorno das aulas presenciais.

Estão adequadas e contribuem para a compreensão da ação das vacinas no corpo humano.

São ações coerentes e que, de fato, conduzem à construção do conhecimento. São ações adequadas e pertinentes para que 0 conhecimento científico possa ser de fato construído e não posto diretamente ao estudante como forma de depósito de informação.

Acredito que sim, especialmente porque acredito que qualquer atividade que inicia uma sequência didática deve envolver uma avaliação das concepções prévias dos alunos, o que é previsto na sequência em questão

De posse da avaliação e da emissão dos pareceres dos cursistas quanto à SD criada, é possível constatar que ela é classificada como sendo pertinente e adequada a seu objetivo. Sua aplicação é apropriada a estudantes do Ensino Fundamental - Anos Finais - e para os estudantes do Ensino Médio. Percebe-se uma complexidade por parte dos estudantes e há necessidade de formação/estudo /preparação por parte dos docentes para a sua aplicação, por causa do desconhecimento da prática.

A seguir, conforme a metodologia de análise adotada, apresentamos as categorias que emergiram da análise dos resultados apresentados. São categorias que evidenciam que a SD deixa clara a complementariedade entre as perspectivas da AC com a da EPP. 


\section{Categoria 1: complementariedade entre a AC e a EPP}

Qual é o propósito de se promover um ensino de ciências que se paute na perspectiva da AC e da EPP? Essa é uma indagação pertinente para este manuscrito uma vez que ter como base a construção de uma SD com este propósito visa pontualmente ao aspecto do desenvolvimento da Alfabetização Científica. E essa, por sua vez, é possibilitadora da concreta cultura científica escolar (SASSERON, 2015).

Assim, desenvolver uma cultura escolar para com a prática da AC com vistas ao desenvolvimento da alfabetização científica é uma urgência para que tal propósito sela alcançado.

Lira e Teixeira (2001, p. 9) ratificam essa confluência entre a AC e a alfabetização científica, quando afirmam que:

Assim, verificamos que a confluência entre a argumentação escrita e a alfabetização científica se apresenta na formação de alunos capazes de utilizarem conceitos e atitudes científicas nas situações cotidianas, considerando os desdobramentos e consequências das suas decisões no exercício do pensar e atuar, conscientemente, para a sustentabilidade do meio ambiente. Os indicadores de alfabetização científica são encontrados mais constantemente nas produções argumentativas.

Tendo posto que a AC é uma prática que possibilita o desenvolvimento da alfabetização científica e essa, por sua vez, torna evidente a complementaridade entre a AC e a EPP, devemos nos ater ao fato de quais ações devem ser desenvolvidas para que essa complementariedade seja efetiva.

Diante de suas práticas para com a interface entre a AC e a EPP, é preciso que o docente esteja apto às instabilidades e saiba flexibilizar suas ações, além de promover as intervenções pertinentes cabíveis para cada situação.

Lira e Teixeira (2020, p. 39-40) enaltecem em sua pesquisa as ações pontuais de docentes que visam a um ensino pautado por esse viés, o qual dialoga com a complementariedade entre a AC e EPP e explicam que que cabe ao docente ver que:

A adesão aos pressupostos que entrelaçam a EPP e a argumentação exige do docente imbuído dessa abordagem formativa escolar e, portanto, voltado a essa vertente argumentativa, o desenvolvimento de determinadas destrezas, entre elas a capacidade de lidar com a instabilidade e a flexibilidade que a pesquisa e a argumentação demandam e a habilidade de mediar processos e propor intervenções.

Contudo a complementaridade em questão requer ações do regente da aula, para que todos os elementos constituintes dessa complementaridade possam ser efetivamente desenvolvidos em sala de aula.

A complementariedade em questão é evidenciada, pois um dos elementos da perspectiva da EPP é a argumentação, sendo mais específico o segundo elemento de sua composição. Logo, é preciso ter a AC como uma prática de peso e constante nas práticas pedagógicas de ensino e, para tanto, o professor deve ser o possibilitador dessa ação, voltando sua prática para efetivas ações que conduzam ao desenvolvimento da habilidade argumentativa.

Sasseron (2015, p. 64-65) enfatiza essa necessidade quando expõe: "Assim, ao colocar a argumentação em prática, o professor traz a possibilidade de desenvolvimento de autoridade epistêmica entre os estudantes." (SASSERON, 2015, p. 64-65). 
A esse respeito, Borges e Lima (2020, p. 38) dialogam em seu trabalho sobre a relação entre AC e EPP, enaltecendo a relação de complementaridade entre essas, quando afirmam que:

Percebe-se, pelo exposto, que as características associadas à perspectiva dialógica se aproximam dos pressupostos da Educação pela Pesquisa. Entre os entrelaçamentos constatados, destaca-se o compartilhamento da necessidade de atribuir uma visão epistêmica à argumentação. Tal aspecto teórico é almejado no exercício da Educação pela Pesquisa, tendo em vista ser a construção de argumentos elencada como uma etapa imprescindível ao processo de reconstrução de conhecimentos.

Logo, podemos dizer que as atividades e ações que se voltam para o desenvolvimento da habilidade argumentativa conduzem o estudante a ações de incorporação e reestruturação de pensamentos, conceitos, significados que levam a sua melhor compreensão e à coesão de uma temática específica.

Enfim, podemos caracterizar essa complementaridade como algo presente entre a AC e a EPP, que está intrínseca a ações de intervenção docente, a qual conduz o estudante à argumentação e à construção do conhecimento. Ou seja, o professor amparado no viés da EPP media a construção e a reconstrução da argumentação que gera o conhecimento.

\section{Categoria 2: maturidade cognitiva}

Ao longo da análise dos pareceres dos cursistas, a SD criada com foco na interface entre a AC e EPP, além da complementariedade observada entre as vertentes citadas, outro aspecto de salutar importância foi apontado e se refere à maturidade dos estudantes para o desenvolvimento da SD em questão. Indagações e questionamentos, ou melhor, afirmações de que a maturidade cógnita adequada dos estudantes para o desenvolvimento desta SD está para a última série dos Anos Finais do Ensino Fundamental (EF), o nono ano, além do Ensino Médio (EM).

Mas, especificamente, a que se refere essa maturidade cógnita? Segundo Jean Piaget, existem quatro períodos em que se observa o desenvolvimento cognitivo. A SD criada foi indicada para o oitavo ano do Ensino Fundamental, Anos Finais, e foi considerada nos pareceres dos participantes desta pesquisa como sendo apropriada a sua aplicação para turmas do nono ano do EF e para o EM. E, segundo o que estabelece Jean Piaget, as referidas séries dos ciclos de ensino se enquadram no desenvolvimento cognitivo operatório formal.

E, na fase cognitiva operatório formal, segundo Nascimento et al. (2020, p. 1-2), "[...] já é possível usar a lógica para todos os problemas concretos [...]" e agrega a esse posicionamento a especificação de Queiroz, Sampaio e Santos (2019, p. 174), quando esses lembram que, na fase cognitiva operatório formal, "[...] o pensamento hipotético-dedutivo, característico do período operatório formal, para o qual seria necessária a construção de abstrações a partir de hipóteses em ações de abstração reflexiva.".

Na perspectiva piagetiana, nessa fase, o raciocínio formal do indivíduo consegue lançar hipóteses, além de restabelecer relações e construir proposições (SARAVALI, 2005).

Desse modo, a fase cognitiva operatório-formal se caracteriza por se enquadrar no aspecto dedutivo, como aponta Saravali (2005, p. 244), quando esse destaca que "O raciocínio assim desenvolvido, com base nas relações das proposições, e não, em seu conteúdo (verdadeiro ou falso), caracteriza-se por ser dedutivo. Assim, é possível ao 
adolescente construir proposições até contrárias aos fatos, em um sistema de múltiplas possibilidades.".

A constatação de que os estudantes não possuem maturidade cognitiva adequada para com a SD em questão é condizente ao panorama atual, já que os professores se queixam de que os estudantes não possuem habilidades para determinada temática e que, dessa forma, se faz necessário o retrocesso da construção de conhecimentos e de habilidades anteriores.

Assim, acreditamos que, mesmo diante do parecer dos participantes dessa pesquisa, quanto ao fato de que a referida SD está mais adequada ao nono ano do EF e ao EM, enfatizamos a necessidade de que essa seja desenvolvida no oitavo ano do EF como uma estratégia de instigar e desafiar os estudantes, com o devido acompanhamento do docente, para que eles superem dificuldades.

Saravali (2005, p. 245) enaltece essa importante ação de desafiar os estudantes para práticas pedagógicas mais elaboradas, quando afirmam que:

Se a escola (e enfatizamos isso na ideia de que são, na grande maioria das vezes, as solicitações do meio escolar que podem favorecer a construção do conhecimento) desde a educação infantil, não solicitar, desafiar e criar condições favoráveis para os constantes equilíbrios e desequilíbrios do sistema cognitivo, afetivo e social, pode acabar gerando um processo de mecanização e repetição.

Assim, é preciso que as atividades dos estudantes dentro do período cognitivo operatório formal tenham suas práticas pedagógicas pautadas em mecanismos de reflexão ao invés dos mecanismos de reprodução, tal atitude os conduziria à adequação cognitiva e à superação das dificuldades que possam vir a apresentar.

\section{Considerações finais}

O presente artigo emergiu da necessidade de se obter o parecer de professores da educação básica a uma SD que se pauta no viés da interface entre a AC e a EPP para a construção do conhecimento científico e da alfabetização científica. Para tanto, essa SD dialoga com um MDM que funde a perspectiva de Toulmin (2006) com a perspectiva de Bonini (2007) e, em concomitância, estabelece práticas e ações pedagógicas prescritas na EPP.

Os pareceres desses professores deixam evidentes a pertinência, a coerência e a adequação da SD como prática pedagógica suficiente para o desenvolvimento do conhecimento científico traçado como objetivo.

Dentre as categorias de análise que emergiram dos resultados, constatou-se a complementariedade entre a AC e a EPP, bem como, a indagação de uma adequada maturidade cognitiva dos estudantes para o desenvolvimento dessa, indicando que essa se enquadra em estudantes que se encontram no período cognitivo operatório formal.

Ratificamos que a referida SD é adequada a esse período cognitivo e, mais especificamente, para o oitavo ano do EF. Caso existam dificuldades por parte dos estudantes, cabe ao docente promover as adequações pertinentes, pois cada docente precisa conhecer como seus alunos assimilam e aprendem para direcionar sua prática.

Por sua vez, a singularidade e/ou o ineditismo deste estudo que está na criação de uma SD que dialoga com a interface entre a AC e a EPP, que por apresentarem 
complementariedade intensificam a possibilidade da construção do conhecimento e da alfabetização científica.

\section{Referências}

BARDIN, L. Análise de conteúdo. Lisboa: Edições 70, 2006.

BECKER, F. O que é construtivismo. São Paulo: FDE, n. 20, 1993, p. 87-93.

BONINI, A. A noção de sequência textual na análise pragmático-textual de Jean-Michel Adam. In: MEURER, J. L.; BONINI, A.; MOTTA-ROTH, D. (Orgs.) Gêneros: Teorias, métodos, debates. $2^{a}$. ed. São Paulo: Parábola, 2007.

BORGES, T.; LIMA, V. A Educação pela Pesquisa como abordagem facilitadora da argumentação dialógica. Revista Insignare Scientia - RIS, v. 3, n. 3, p. 25-45, 13 nov/2020.

DEMO, P. Pesquisa Participante: Saber pensar e intervir juntos. 2a . ed. Brasília (DF): Liber, 2008.

GALIAZZI, M. C; MORAES, R. Educação pela pesquisa como modo, tempo e espaço de qualificação da formação de professores de ciências. Ciênc. Educ. Bauru, v. 8, n. 2, 2002, p. 237-252. DOI: http://dx.doi.org/10.1590/S1516-73132002000200008.

GALIAZZI, M. C; MORAES, R. Educar pela pesquisa. 9a. ed. Campinas: Autores Associados, 2011.

JIMÉNEZ ALEIXANDRE, M. P. 10 Ideas clave. Competencias en argumentación y uso de pruebas. Educatio Siglo XXI, v. 29, n. 1, 2011, p. 363-366.

JIMÉNEZ-ALEIXANDRE, M. P.; DÍAZ DE BUSTAMANTE, J. Discurso de aula y argumentación en la clase de Ciências: Cuestiones teóricas y metodológicas. Enseñanza de las Ciencias. Barcelona, v. 21, n. 3, 2003, p. 359-370.

JIMÉNEZ-ALEIXANDRE, M. P.; BROCOS, P. Desafios metodológicos na pesquisa da argumentação em ensino de ciências. Ensaio Pesquisa em Educação em Ciências (Belo Horizonte), v. 17, n. spe, 2015, p. 139-159.

KELLY, G. J. Inquiry, activity and epistemic practice. In: DUSCHL, R.; GRANDY, R. (Eds.).

Teaching Scientific Inquiry: Recommendations for research and implementation. Rotterdam: Sense Publishers2008, p. 99-117.

KRASILCHIK, M.; MARANDINO, M. Ensino de Ciências e cidadania. 2ª ed. São Paulo: Moderna. 2007

LEITÃO, S. O lugar da argumentação na construção do conhecimento. In: LEITÃO, S.; DAMIANOVIC, M. C. (Orgs.). Argumentação na escola: O conhecimento em construção. Campinas: Pontes Editores, 2011.

LIMA, V. M do R. A sala de aula do Educar pela Pesquisa: Uma história a ser contada. 2004. Tese. Doutorado em Educação em Ciências e Matemática. Pontifícia Universidade Católica do Rio Grande do Sul, Porto Alegre, 2004. 
LIRA, M.; TEIXEIRA, F. M. Alfabetização científica e argumentação escrita: Proposições reflexivas. In: VIII Encontro Nacional de Pesquisa em Educação em Ciências e I Congreso Iberoamericano de Investigación en Enseñanza de Las Ciencias. Campinas, 2001.

MÉKSENAS, P. Aspectos metodológicos da pesquisa empírica: A contribuição de Paulo Freire. Revista Espaço Acadêmico. Maringá (PR), ano VII, n.78, nov. 2007.

MORAES, R.; GALIAZZI, M. C.; RAMOS, M. G. Pesquisa em sala de aula: Fundamentos e pressupostos. In: MORAES, R.; LIMA, V. M. R. Pesquisa em sala de aula: Tendências para a educação em novos tempos. $1^{\text {a }}$. ed. Porto Alegre: Edipucrs, 2002. p. 9-23.

NASCIMENTO, M. E. S. et al. Sequência didática para auxiliar no desenvolvimento da coordenação motora fina no período de transição da letra.

PEZARINI, A. R.; MACIEL, M. D. As dimensões da argumentação no ensino de Ciências em pesquisas de 2007 a 2017: Um olhar para a caracterização e para as ferramentas metodológicas para estudar esta temática. Amazônia: Revista de Educação em Ciências e Matemáticas, [S.I.], v. 14, n. 32, p. 61-77, dez. 2018. ISSN 2317-5125.

QUEIROZ, R. L.; SAMPAIO, F. F.; SANTOS, M. P. DuinoBlocks4Kids: utilizando Tecnologia Livre e materiais de baixo custo para o exercício do Pensamento Computacional no Ensino Fundamental I por meio do aprendizado de programação aliado à Robótica Educacional.

Revista Brasileira de Informática na Educação - RBIE. V. 27, N. 2, 2019, p. 167-197.

RAMOS, M. G. Os desafios da educação pela pesquisa: Dos limites da realidade às possibilidades de educar para a argumentação. In: IV ANPEd-SUL - Seminário de Pesquisa em Educação da Região Sul, Anais. Porto Alegre, 2000. CD.

SARAVALI, E. G. A psicopedagogia na educação superior: Contribuiç̧̃es da teoria piagetiana. Revista Psicopedagogia, v. 22, n. 69, 2005, p. 243-253.

SASSERON, L. H. Alfabetização científica, ensino por investigação e argumentação: Relações entre ciências da natureza e escola. Ensaio Pesquisa em Educação em Ciências (Belo Horizonte), v. 17, 2015, p. 49-67.

SILVA, A. H. et al. Análise de conteúdo: Fazemos o que dizemos? Um levantamento de estudos que dizem adotar a técnica. Conhecimento Interativo, v. 11, n. 1, 2017, p. 168-184.

TANDON. R. Participatory Research in the Empowerment of People. Convergence, v. 14, n. 3, 1981, p. 20-27.

TOULMIN, S. E. Os usos do argumento. São Paulo: Martins Fontes, 2ª ed., 2006.

VIEIRA, R. D. et al. Argumentação e orientações discursivas na educação em ciências. Ensaio Pesquisa em Educação em Ciências, v. 17, n. 3, 2015, p. 707-725. 
Apêndice

\section{Sequência Didática - Relação entre argumentação e educação pela pesquisa}

Série/Ano: $8^{\circ}$ ano dos Anos Finais do Ensino Fundamental

Título

Conteúdo

Habilidade

Público-alvo

Tempo estimado

Por que me vacinar contra o vírus da Covid 19?

Vírus e vacinas

Compreender as relações entre vírus e vacinas, por intermédio de práticas da educação pela pesquisa.

Objetivo geral

Estudantes do $8^{\circ}$ ano

05 horas/aula

Possibilitar a construção do conhecimento, para que os estudantes possam

tomar decisões relativas à melhoria na qualidade de vida.

Objetivo específico

Desenvolver as etapas da educação pela pesquisa com vistas à construção do conhecimento sobre vírus e vacinas.

Material de apoio Vídeo do Youtube.

$1^{\circ}$ momento - Questionamento - 2 aulas

Para essa primeira fase, o docente lança a seguinte questão problema: Por que me vacinar contra 0 vírus do Covid 19?

Na sequência, o docente, como estratégia de provocação, faz uso do vídeo disponível no Youtube, https://www.youtube.com/watch?v=Spf10C9ceWE que descreve a ação de uma infecção e a atuação das vacinas no organismo vivo.

Após essa sensibilização, os alunos são instigados a produzir perguntas relacionadas à temática e, como hipóteses de resolução à questão-problema lançada.

Seguimos com o momento de socialização das questões-problema elencadas pelos estudantes.

$\mathrm{Na}$ sequência, o docente solicita que, para a próxima aula, os estudantes façam uma pesquisa par construir um referencial teórico sobre esta indagação: Por que me vacinar? Como resposta, deveriam oferecer uma resposta sintética de, no máximo, 15 linhas.

A aula seguinte deve ser dedicada a uma roda de conversa com a exposição e discussão das pesquisas realizadas pelos estudantes. $O$ docente, nesse caso, pausa a aula depois da explanação de cada estudante, para construir no quadro negro uma síntese fiel e com informações adequadas acerca das pesquisas.

Os estudantes, no fim das discussões, devem tomar nota dessa construção conjunta, pois será utilizada no 3ํㅡㄹ momento dessa aula, a que se dedicará à validação da argumentação construída.

$2^{\circ}$ - momento - Argumentação científica - 2 aulas

Para a produção da argumentação científica, faz-se uso da proposta do Modelo Didático Misto de Pezarini (2020, p. 347).

Legenda:

$\mathrm{D}=$ Dado; $\mathrm{Q}=$ Qualificadores modais; $\mathrm{C}=$ Conclusão; $\mathrm{W}=$ Garantia; $\mathrm{B}=$ Apoio; $\mathrm{R}=$ Refutação.

$\mathrm{PQ}=\mathrm{a}$ ação se inicia com um Por quê?

$E X=O$ Por quê? Promove uma explicação;

$\mathrm{CO} / \mathrm{AV}$ = gera uma conclusão/avaliação;

$\mathrm{DES}=$ descrição inicial da refutação;

$\mathrm{ORD}=$ de odo a quebrar a ordem estabelecida;

REA/AVA = a quebra gera reações e avaliações;

RES = em busca da resposta;

$\mathrm{EQ}=$ para restabelecer 0 equilíbrio 


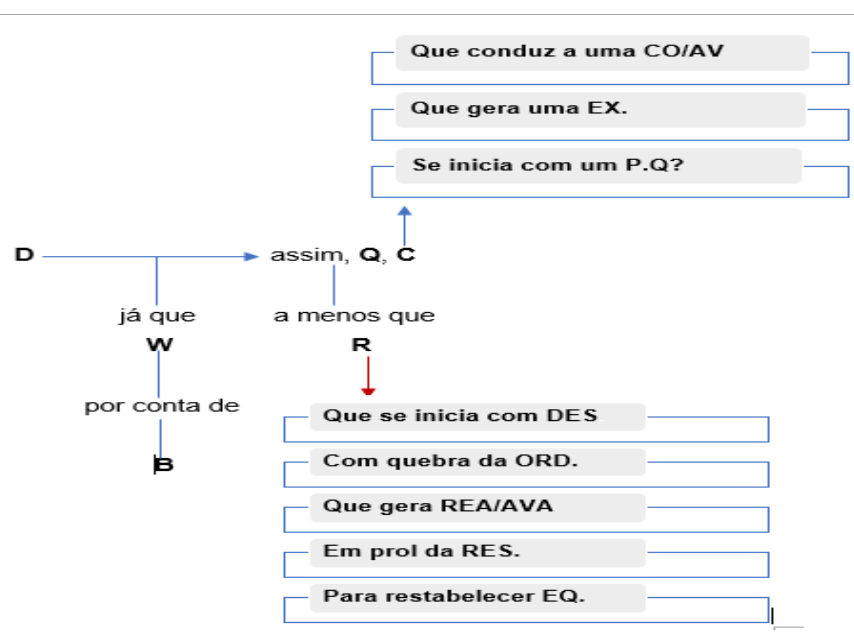

Para a construção da argumentação, recorremos ao MDM apresentado. Esse modelo faz uso do Padrão de Toulmin como base para a construção da argumentação, no entanto conduz a que a conclusão se faça por intermédio da sequência explicativa de Bonini (2007) e a refutação seja construída por sua vez pela sequência narrativa do mesmo autor.

Um exemplo de construção da argumentação a partir desse MDM.

Dado: As vacinas constroem a resposta imune contra o Covid 19.

Conclusão: Porque promove a geração de anticorpos, que são moléculas de defesa do organismo, destruindo os antígenos específicos. Assim, se produz uma memória imunológica capaz de atacar os antígenos quando esses invadirem o organismo.

Garantia: ativam a produção de anticorpos

Apoio: recebemos o antígeno atenuado no organismo que, por estar "enfraquecido", não causa a doença, mas ativa o sistema imune a produzir anticorpos.

Refutação: A menos que essa vacina não possua o antígeno atenuado. O princípio básico da vacina é a prevenção e, por esse motivo, é utilizado o antígeno atenuado. Assim, se não possui o antígeno atenuado, o organismo receberá o antígeno ativo que causará a doença. Por esse motivo, os antígenos são atenuados em laboratório antes de serem usados na produção das vacinas, para que a vacina se constitua como de fato um mecanismo de prevenção e proteção.

$3^{\circ}$ momento - Validação da argumentação - 1 aula

Para a validação da argumentação, recorremos à sustentação dos argumentos por meio de interlocutores teóricos. Para tanto, devemos instigar e conduzir os estudantes à construção/produção escrita com essa interlocução entre argumento e teoria, de modo que, com essa ação,

fundamentemos e exemplifiquemos os argumentos com dados de fontes, sejam elas empírica ou de exemplos teóricos.

Recorrer à construção do referencial teórico do $1^{\circ}$ momento dessa sequência para construir a validação da argumentação construída. Ou seja, orientar os estudantes a escreverem um pequeno parágrafo que valide/ratifique a argumentação por ele criada.

\section{Avaliação}

Das construções, sejam elas na forma oral ou escrita ao longo de todo o processo. A avaliação, numa perspectiva de mediação, acompanha todas as etapas da produção em um processo de educação pela pesquisa, realizada por meio do diálogo e de crítica constantes, a avaliação passa a ser função não só do professor, mas de todos os participantes.

\section{Referências}

PEZARINI, A. R. Construção e avaliação dos argumentos e das argumentações produzidas por estudantes de Ciências e de Biologia. 339 f. Tese (Doutorado em Ensino de Ciências e Matemática). Universidade Cruzeiro do Sul, São Paulo, 2020. Disponível em: https://repositorio.cruzeirodosul.edu.br/handle/123456789/983. 